\title{
TRENDS IN PENSION INSURANCE
}

\author{
D. Shterev* \\ Department of Social Activities, Faculty of Medicine, Trakia University, Stara Zagora, Bulgaria
}

\begin{abstract}
This article deals with a topical for our country problem which is related to the State Social Insurance. It provides a review of the factors having an adverse effect onto the financial state of the Bulgarian pension system. Discussed are the basic parameters related to the economic incentives in connection with the optimal functioning of the pension system.
\end{abstract}

Key words: pension system, State Social Insurance, actuarial analysis, standard of living, insurance contributions.

Among the EU member states, our county features the worst demographic and migration indicators, financial stability and standard of living, which respectively directly and indirectly is influencing and posing a number of problems in the present and future development of the pension insurance system in Bulgaria.

In 2010, the ratio of the non-working age population (over 65 years) to the working- age population (aged 15-64) is $25 \%$ which in 2020 is likely to reach $30 \%$ and in $2060-57 \%$ in accordance with the actuarial analysis of the Bulgarian Nasional Social Security Institute (NSSI).

Pessimistic are also the forecasts of the National Statistical Institute of Bulgaria with reference to Bulgaria's total population steady decline. In 2010 the population of Bulgaria is 7 528000 people, however the prospects for 2060 are only for 5475000 people in the best possible case.

The actuarial analysis of the Bulgarian Ministry of Finances based on the NSSI data base, show that the expenses under the funds of the State social insurance will be constantly exceeding the revenues, and in 2050 the balance will be negative $(-15,5 \%)$.

\footnotetext{
*Correspondence to: Dimitar Shterev, Trakia University, Faculty of Medicine, Department of Social Activities, 11 "Armeiska" street, 6000, Stara Zagora, Bulgaria, e-mail: soc.dein@abv.bg, telephone: 042 644-417
}

Based on the reports and the forecasts of the National Social Security Institute, the trends clearly show that more funds will be needed to secure the long-term payments (pensions) from the State social insurance system (Figure 1).

Among the negative factors contributing for the poor financial state of the country's pension system are also the big share of the grey economy, the low income level and/or constant pay levels, unemployment rate, instability in the pension scheme legislation after a series of inadequate and populist political decisions creating conditions for losing confidence in its viability, especially on side of the young age groups of people; the early retirement scheme suggested by the so-called "hidden" or "4th" labor category which is applied for the security sector staff (employees under the auspices of the Bulgarian Ministry of Interior and the Special Forces, members of the Armed Forces, etc.); gender discrimination in retirement; enjoyment of rights, relevant pension amount and period.

Last but not least, are to be mentioned the negative factors and causes such as the increased levels of misuse related to enjoyment of rights (benefits, allowances, pensions) from the social insurance system as a result of inappropriate actions of the members of the Medical Expert Advisory Committees; accounting for the actual insurance contribution status upon determining the amount of the payable benefits, allowances, pensions and the relevant period; collectability of revenue and in particular the social insurance contributions; the sinking public confidence in terms of the pension insurance companies; the scope of the social insurance plans with regard to the self-insured persons, etc. 


\section{ANNUAL EXPENSES, BGN}

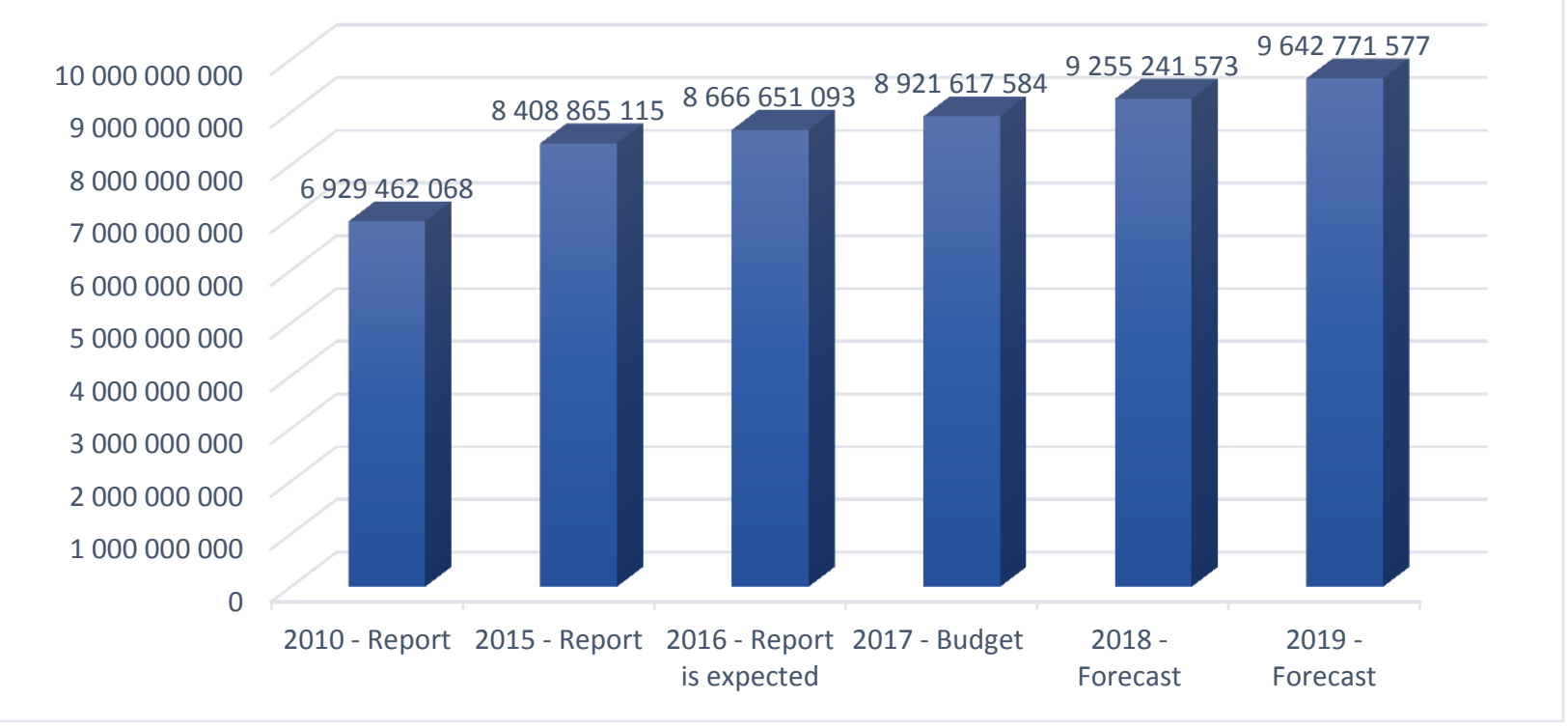

Figure 1. Annual Expenses, BGN

In my personal opinion, of significant importance is also the accumulation of payments which are irrelevant and not linked with the insurance contribution through the so- called "Non-Employment-Linked Pensions Fund" in the State Social Insurance according to information provided by the National Social Security Institute (Figure 2):

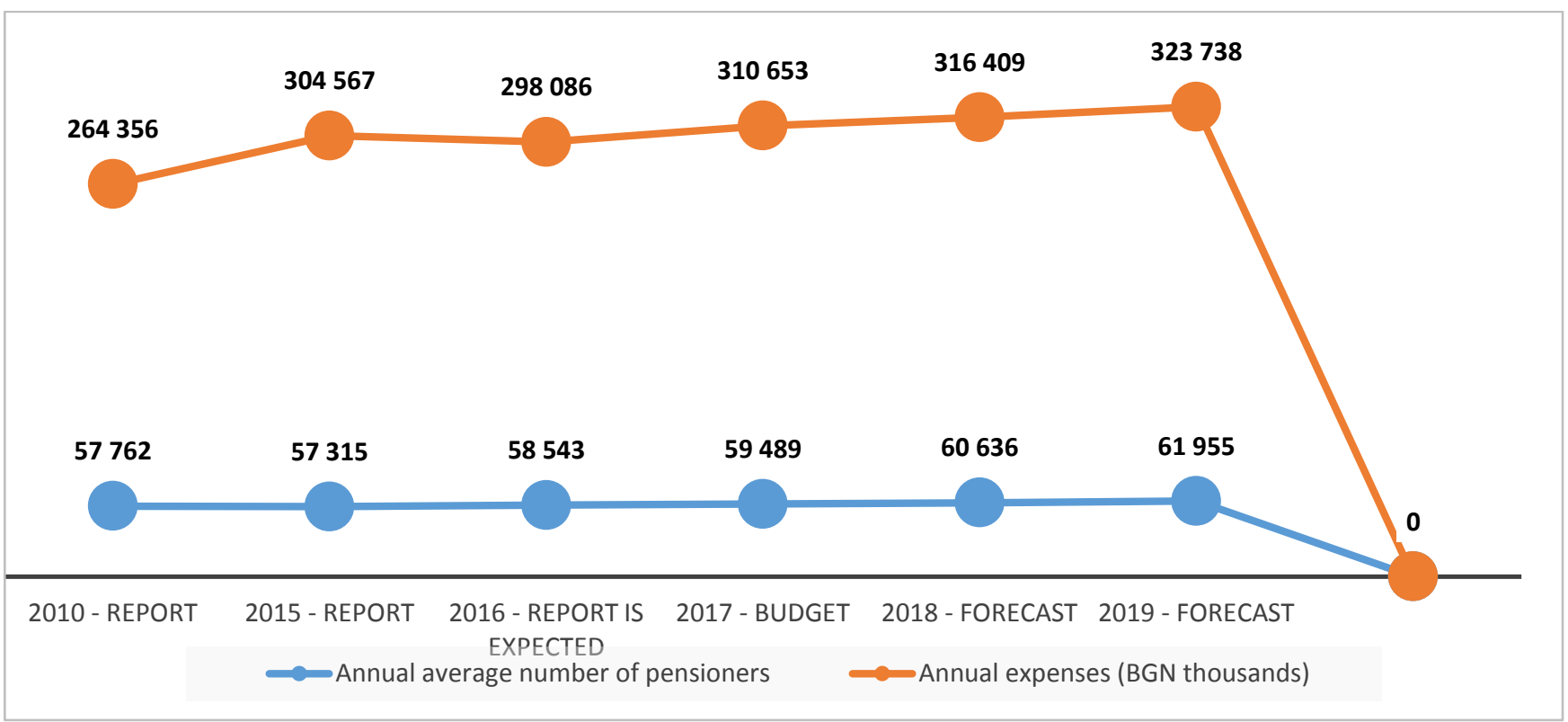

Figure 2. Annual average number of pensioners and annual expenses

As a result of the observations over the recent years, and an analysis of what has been achieved so far, as well as the trends in the field of pension insurance, clearly and unconditionally it can be concluded that the pension insurance system needs to be upgraded by a set of transparent, adequate and targeted actions and reforms in order to guarantee its stability. Those can be outlined as it follows:

$>$ Economically justified and financially reasonable measures, but not political decisions. This should take place along with a regular monitoring and update of the actuarial analysis after changes in the initial parameters of the demographic characteristics and economic indicators

Linking the benefits, allowances and pensions with the insurance contributions by introducing limitation in the amounts administratively determined, and also by abolishing the pension ceiling and the Maximum Insurable Earnings Ceiling, and in the long run-the minimum insurance thresholds. 
Introducing of economic incentives and not only administrative measures in order to provide for a higher insurance contribution. This can take place on the grounds of tax relief.

$>$ Determining the financial parameters for the proper functioning of the social security system. In terms of revenue, these shall comprise of the amount of the insurance contributions, the insurable earnings and the range of the insured persons.

$>$ Establishing of a permanent structure with the participation of experts from the relevant institutions for continuous monitoring, evaluation and development proposals.

$>$ Better information and staff management, i.e. unconditionally discontinuing the practice of annual staff optimization within the NASSI.

$>$ Limiting the expenses of the system which are not linked with the actual insurance contribution. This requires a focus on the early retirement schemes, acquiring of rights on preferential terms, allowance of disability pensions, etc.

Sanitation of the State social insurance in terms of all non-specific functions related mostly with administration of benefits and allowances which are irrelevant and not linked with the insurance contribution and a major part of which are within the subject and the scope of the social support sector.

> Introducing of mandatory and up-to-date rules for the risk assessment of the pension insurance companies and the pension funds managed by them.

$>$ Set up of an investment reserve to secure the pension payments made by the pension insurance companies in connection with a negative return and for the relevant period of time.

After changes in the legislation, creating possibilities for temporary changes in the investment restrictions upon a decision of the Financial Surveillance Commission in case of a force majeure event such as a financial crisis.

$>$ Changes in the organization and stricter control on the collectability of the insurance contributions by setting up a competent department at the National Revenue Agency.

$>$ Changes in the legislative system allowing better control by the Ministry of Health over the work of the Medical Expert Advisory Committees and the documentation issued by them

$>$ Enhanced incentives and motivation for a more active participation in the social insurance system (e.g. deferred retirement, etc.) 